This document is confidential and is proprietary to the American Chemical Society and its authors. Do not copy or disclose without written permission. If you have received this item in error, notify the sender and delete all copies.

\title{
Protein-free hapten-carbon nanotube constructs induce the secondary immune response
}

\begin{tabular}{|r|l|}
\hline Journal: & Bioconjugate Chemistry \\
\hline Manuscript ID & bc-2016-00653u.R2 \\
\hline Danuscript Type: & Article \\
\hline Date Submitted by the Author: & $25-$ May-2017 \\
\hline & $\begin{array}{l}\text { Ceballos-Alcantarilla, Eric; Universitat de Valencia } \\
\text { Abad-Somovilla, Antonio; Valencia University, Organic Chemistry } \\
\text { Agulló, Consuelo; Universitat de València, Organic Chemistry } \\
\text { Abad-Fuentes, Antonio; IATA-CSIC, Biotechnology } \\
\text { Mercader, Josep; IATA-CSIC, Biotechnology }\end{array}$ \\
\hline
\end{tabular}

\section{SCHOLARONE \\ Manuscripts}


1

2

3

4

5

6

7

8

9

10

11

12

13

14

15

16

17

18

19

20

21

22

23

24

25

26

27

28

29

30

31

32

33

34

35

36

37

38

39

40

41

42

43

44

45

46

47

48

49

50

51

52

53

54

55

56

57

58

59

60

\title{
Protein-free hapten-carbon nanotube
}

\section{constructs induce the secondary immune}

\section{response}

\author{
Eric Ceballos-Alcantarilla, ${ }^{a}$ Antonio Abad-Somovilla, ${ }^{a}$ Consuelo Agulló, ${ }^{a}$ Antonio Abad-Fuentes, ${ }^{b}$ \\ Josep V. Mercader ${ }^{\mathrm{b}, *}$ \\ a Department of Organic Chemistry, Universitat de València, Doctor Moliner 50, 46100 Burjassot, \\ València, Spain \\ ${ }^{b}$ Department of Biotechnology, Institute of Agrochemistry and Food Technology (IATA), Spanish \\ National Research Council (CSIC), Agustí Escardino 7, 46980 Paterna, València, Spain \\ * Corresponding author email: jvmercader@iata.csic.es; tel. +34-963900022; fax +34-963636301.
}




\begin{abstract}
Carbon nanotubes are novel technological tools with multiple applications. The interaction between such nanoparticles and living organisms is nowadays a matter of keen research by academic and private institutions. In this study, carbon nanotube constructs were investigated as delivery vehicles for immunostimulation and induction of the secondary immune response to a small organic molecule, namely a hapten. Two types of nanoconstructs were prepared: on the one hand, carbon nanotubes carrying a protein bioconjugate of a hapten covalently linked to the carbon surface, and on the other hand, covalent carbon nanotube constructs of the same model chemical compound without the carrier protein. Nanotube vehicles carrying a hapten-protein bioconjugate were demonstrated to stimulate the immune system and to induce a strong primary immune response against the hapten with as low as $0.1 \mu \mathrm{g}$ of the model chemical. The influence of the different elements of those nanoconstructs over the immune response was investigated to better understand the molecular mechanisms that are involved. As expected, the presence of the carrier protein was shown to be necessary in order to trigger the immune response. Interestingly, we found that a remarkable secondary immune response to the model organic compound occurred in the absence of a carrier protein. Additionally, a satisfactory adjuvant effect of carbon nanotubes was observed and a potent immune response was elicited without employing an oil-based adjuvant.
\end{abstract}




\section{INTRODUCTION}

The immune system of vertebrates protects the organism from a large variety of infectious diseases. Upon a novel infection, the innate and the adaptive immune systems are activated and a cascade of events occurs, called the primary immune response. The innate immune system is the prompt reaction to foreign bodies in which a number of effectors are involved, such as the complement system and leukocytes. The adaptive immune system is antigenspecific and provides a long lasting protection; the ability to generate immune memory is the key attribute of this system. In order to achieve high efficiency, multiple antigen processing and naïve cell maturation cycles take place. ${ }^{1,2}$ Briefly, whole cells and particulate matter are phagocytosed very efficiently by cells of the immune system which generate peptide fragments that are exposed to the surrounding media by the major histocompatibility complex I (MHC I) of nucleated cells and by the $\mathrm{MCH}$ II of different professional antigenpresenting cells, thus triggering the specific immune response. ${ }^{3} \mathrm{~T}$ helper cells are activated by the displayed peptides, proliferation of plasma and memory B cells is stimulated, and antibodies specific to that particular antigen are originated. ${ }^{4}$ Upon additional exposures to the same antigen, the secondary immune response is launched. The innate immune system is turned on again and particular memory B cells of the adaptive immune system that were formed during previous infections are rapidly stimulated so antibodies can be immediately generated. As a result, cells that express antibodies with high affinity to the antigen proliferate preferentially, thereby increasing the concentration of specific and high-affinity antibodies in the serum. ${ }^{5,6}$ This phenomenon is known as maturation of the immune response.

A wide variety of materials with unique characteristics are available nowadays whose properties and complete potential applications are still to be discovered. Novel functionalities of bioconjugates are considerably being investigated in the biotechnology field for industrial, analytical, and medical purposes. Particularly, the response of the immune system of 
vertebrates to nanomaterials constitutes currently an open debate, not only from the toxicological point of view but also as desirable immunostimulatory or immunosuppressive means. $^{7,8}$ Moreover, artificial immunization for vaccination or antibody production using bioconjugates as nanovehicles is a highly relevant subject for the research and industrial sectors. Present scientific studies show that a variety of nanoparticles can avoid, stimulate or suppress the immune response, and that their interaction with the immune system is mainly determined by their size, shape, charge, and surface chemistry. ${ }^{9}$ Antigens can be entrapped, adsorbed or covalently immobilized to the surface of the particles, thus allowing a gradual release ${ }^{10-12}$ and an adequate delivery. ${ }^{13,14}$ Nanoparticles can activate humoral and cellmediated immune responses by interacting with plasma proteins and cell receptors, and they can be internalized by mammalian cells. For instance, a number of authors have described the employment of gold nanoparticles as adjuvants, rendering titers comparable to or higher than those obtained by traditional procedures such as aluminum salt and Freund's adjuvants. ${ }^{15-17}$ Moreover, those nanostructures have been known for decades to induce antibody production towards antigens. ${ }^{18,19}$ Nowadays, different sorts of immunomodulatory bioconjugates for drug, gene and antigen delivery are being investigated, such as dendrimers, ${ }^{20}$ liposomes, ${ }^{21}$ metallic nanobeads, ${ }^{22-24}$ biodegradable polymers, ${ }^{25,26}$ polymeric synthetic particles, ${ }^{27-30}$ carbon nanotubes (CNTs), ${ }^{31-33}$ etc.

CNTs have been demonstrated to perform adequately as peptide or protein carriers for animal immunization. ${ }^{34-36}$ Moreover, high titers and excellent antibody affinities to haptens (low molecular-weight compounds) have been obtained in our laboratory using a hapten-toprotein bioconjugate covalently immobilized onto $\mathrm{CNTs}^{33}$ - even with just $0.05 \mu \mathrm{g}$ of bioconjugate per boost. In that previous study, we generated antibodies to a small synthetic chemical using single-walled (SWNT) and multi-walled (MWNT) CNTs of different lengths, and a clear structure-activity relationship was observed. The shortest and thickest (MWNT $0.5 \mu \mathrm{m}$ long) CNT-based immunogen afforded the best immune response, probably because such 
nanotubes were better phagocytosed by antigen-presenting cells - CNTs mimic the size and shape of microorganisms, though the details of nanoparticle internalization are largely unknown. Additionally, hydrophobicity and surface antigen density could have played a role in our previous results. Controversy exists regarding the interaction of CNTs with the complement system. ${ }^{37}$ It seems that pristine SWNTs activate the complement system by the classical pathway, whereas MWNTs can do it by both the classical and the alternative pathways. ${ }^{32}$ However, interaction of chemically functionalized CNTs with the complement could vary depending on the nature of each particular modification.

Additional rational studies concerning the interaction between nanoparticles and the immune system are required in order to discover novel applications and to enhance a more comprehensive understanding of host immunity. Moreover, with the increasing demand of new types of vaccines and the growth and diversification of the biotechnological uses of antibodies, there exists a critical need for alternative delivery vehicles with adjuvant properties. In the present study, we have employed CNT-based covalent constructs carrying a small chemical compound (hapten) for stimulation of the immune system in laboratory animals. The aim was to induce a strong immune response towards the hapten using CNTs with or without a carrier protein and using minute quantities of the hapten. The adjuvant capacity of those nanoconstructs was investigated and ethical aspects of animal welfare were considered.

\section{RESULTS AND DISCUSSION}

Preparation of CNT-based Immunogens. The capability of CNT-based peptide or protein constructs to induce the adaptive immune response has been demonstrated and studied during the last years. ${ }^{38,39}$ Functionalized nanotubes resemble bacteria in size and shape which probably contributes to activate the immune system of vertebrates. Macrophages are able to phagocyte CNT particles and any peptide or protein molecule attached to the particle can be 
processed and displayed by the MHC, thus the intricate antibody generation cascade is triggered. Recently, we demonstrated that immunogens using hapten-protein bioconjugates covalently immobilized onto CNTs can induce high titers and generate high-affinity antibodies to the carried hapten. ${ }^{33}$ Now, we have gone further by studying the immunizing capacity of CNT-based constructs of haptens without the participation of a carrier protein.

In the present study, we have used short and thick multiwall CNTs, less than $1 \mu \mathrm{m}$ long $(0.8-1.0 \mu \mathrm{m})$ and approximately $50-80 \mathrm{~nm}$ in diameter, readily prepared from commercial MWNTs via an oxidative fragmentation promoted by $\mathrm{HNO}_{3}$ at high temperature under microwave irradiation (Figure 1). The generated carboxylate moieties at the end and on the sidewalls of the resulting acid-cut CNT fragments (CNT-COOH) were chemically modified by microwave-assisted condensation with ethylenediamine in dimethylsulfoxide to give the corresponding amino-functionalized CNTs $\left(\mathrm{CNT}-\mathrm{NH}_{2}\right)$. Both the initial incorporation of negatively charged carboxylate groups on the surface of the CNTs and its subsequent transformation into the corresponding positively charged amino moieties were confirmed by the change in the sign of the zeta potential of their aqueous suspensions which undergoes a change from zero to negative after the oxidative treatment of the pristine MWNTs (CNT$\mathrm{COOH}, \zeta=-36.3 \mathrm{mV}$ ) and then passes to positive after introduction of the amine groups (CNT$\mathrm{NH}_{2}, \zeta=+23.8 \mathrm{mV}$ ). The aminated CNTs thus obtained afforded a stable suspension in water (at $1 \mathrm{mg} / \mathrm{mL}$ ) that could be maintained at $4{ }^{\circ} \mathrm{C}$ for long periods of time (more than 4 months).

For the preparation of the CNT-based immunogens, we used hapten PPm (Figure 1). This hapten is a derivative of penthiopyrad, a representative member of the succinate dehydrogenase inhibitors group of fungicides. ${ }^{40}$ The synthetic hapten incorporates a 
carboxylate group at the end of the penthiopyrad hydrocarbon branched chain that enables its covalent attachment, via an amide bond, to the protein or the amino functionalized CNTs. Hapten PPm was covalently linked to CNTs and to the carrier protein using the purified active ester of the hapten, rather than using a one-pot coupling reaction; thus, no undesirable secondary reactions could take place and higher coupling yields could be reached.

The preparation of the CNT-based immunogens was completed by covalent conjugation of the free amino groups of the CNT-NH$H_{2}$ particles to the BSA-PPm bioconjugate (Figure 1), or directly to the own PPm hapten. In both cases, conjugation implies the condensation between the amino groups of CNT-NH$H_{2}$ with the carboxylate groups of BSA or hapten PPm, which was undertaken using standard bioconjugation techniques. The properties of these functionalized CNTs are listed in Table 1. The distribution of the bioconjugate BSA-PPm over the CNT walls was qualitatively determined by immuno-TEM. Basically, this implies the labeling of the CNT- 
BSA-PPm particles with the anti-PPm polyclonal antibody PPm\#2 and then incubation with a gold-labeled goat anti-rabbit IgG antibody. Figure 2 shows the immuno-TEM image of one of these CNT-BSA-PPm immunizing constructs in which it can be clearly observed (black and round spots) the presence of single molecules of BSA-PPm covalently immobilized on the surface of the functionalized CNT.

Table 1. Properties of Functionalized Nanotubes

\begin{tabular}{|c|c|c|c|c|c|}
\hline & CNT & CNT-COOH & CNT-NH ${ }_{2}$ & CNT-BSA-PPm & CNT-PPm \\
\hline zeta potential (mV) & 0 & $-36.3 \pm 0.7$ & $+23.8 \pm 1.1$ & $-32.5 \pm 1.0$ & $+6.9 \pm 0.8$ \\
\hline $\begin{array}{l}\text { solubility in water } \\
\qquad(1 \mathrm{mg} / \mathrm{mL})\end{array}$ & none & high & $\begin{array}{l}\text { medium } \\
\text { to high }\end{array}$ & high & poor \\
\hline $\begin{array}{l}\text { bioconjugate density } \\
\qquad(\mu \mathrm{g} / \mathrm{mg} \text { of } \mathrm{CNT})\end{array}$ & - & - & 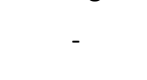 & 2.6 & - \\
\hline $\begin{array}{l}\text { hapten density } \\
(\mu \mathrm{g} / \mathrm{mg} \text { of } \mathrm{CNT}) \\
\text { Hapten-to-protein mol }\end{array}$ & - & BSA-PPr r r r & tate & $0.26\left(\mathrm{MR}^{\mathrm{a}} 18\right)$ & 0.1 \\
\hline
\end{tabular}

Table 2. Immunization Procedures Used to Study the Immune Response with CNT-based Immunogens

\begin{tabular}{|c|c|c|c|c|}
\hline \multirow[b]{2}{*}{ procedure } & \multicolumn{2}{|c|}{ immunogen } & \multirow{2}{*}{$\begin{array}{c}\text { BSA bioconjugate } \\
\text { load }(\mu \mathrm{g})\end{array}$} & \multirow{2}{*}{$\begin{array}{l}\text { hapten } \\
\text { load }(\mu \mathrm{g})\end{array}$} \\
\hline & injection 1 & injections 2 to 5 & & \\
\hline A & CNT-BSA-PPm & CNT-BSA-PPm & 2 & 0.1 \\
\hline B & CNT-BSA-PPm & CNT-PPm & $0^{a}$ & 0.1 \\
\hline C & BSA-PPm & BSA-PPm & 2 & 0.1 \\
\hline D & CNT-BSA-PPm & CNT-NH ${ }_{2}+\mathrm{PPm}^{\mathrm{b}}$ & $0^{a}$ & 0.1 \\
\hline$E$ & CNT-PPm & CNT-PPm & 0 & 0.1 \\
\hline
\end{tabular}

${ }^{\mathrm{a}}$ Except for the first injection which contained $2 \mu \mathrm{g}$ of BSA bioconjugate. ${ }^{\mathrm{b}} \mathrm{A}$ mixture of 1 $\mathrm{mg}$ of CNT- $\mathrm{NH}_{2}$ and $0.1 \mu \mathrm{g}$ of hapten was used without covalent linking.

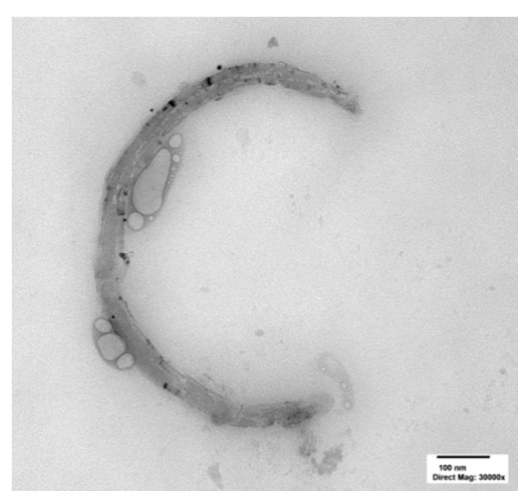

Figure 2. Electron microscopy images $\left(3 \times 10^{4}\right)$ of a CNT-BSA-PPm immunizing construct. 
Secondary Immune Response. Four sets of animals were immunized with a series of immunogens - all of them carrying the same low hapten load $(0.1 \mu \mathrm{g})$ - that were emulsified with Freund adjuvant. In order to evaluate whether or not the carrier protein is necessary to induce the secondary immune response when CNT-based constructs are employed, different procedures involving covalent constructs of CNT-protein conjugate or CNT-hapten were evaluated (Table 2, procedures A, B, C, D, and E). As expected, no immune response was detected when CNT-PPm construct was used as immunogen from the first to the last injection (Figure 3, procedure E) probably, among other reasons, because the lack of protein prevented the MHC from displaying the hapten due to the absence of a peptide conjugate. On the contrary, high titers $\left(10^{5}\right)$ and $\mathrm{IC}_{50}$ values in the low nanomolar range could be reached when the immunizing construct carried BSA (CNT-BSA-PPm) throughout the entire immunization process (procedure A). Those results were achieved with very low doses of protein bioconjugate immobilized onto the CNTs, i.e., 50 times lower than a regular immunization procedure without nanotubes (Table 1). It was observed that, after three injections pursuant to procedure A, titers reached a plateau and the final high affinity of the raised antibodies was already attained (Figure 3). On the other hand, if only the first injection was supplied with CNT-BSA-PPm construct and protein-free CNT-based constructs were administered in subsequent boosts (procedure B), the immune response was matured, i.e., titers were increased and $\mathrm{IC}_{50}$ values were lowered. Titer values, in this case, reached a plateau after the second injection whereas more injections seem to be necessary in order to achieve a minimum $\mathrm{IC}_{50}$ value. Qualitatively, antibodies obtained using CNT-PPm construct for maturation of the immune response (procedure B) showed equivalent titers and affinities after the fifth boost dilution factors were between $3 \times 10^{4}$ and $10^{5}$ and $I C_{50}$ values were in the low nanomolar range - to those attained with immunizations using CNT-BSA-PPm construct throughout the whole process (procedure A). This result suggests that maturation of the immune response could 

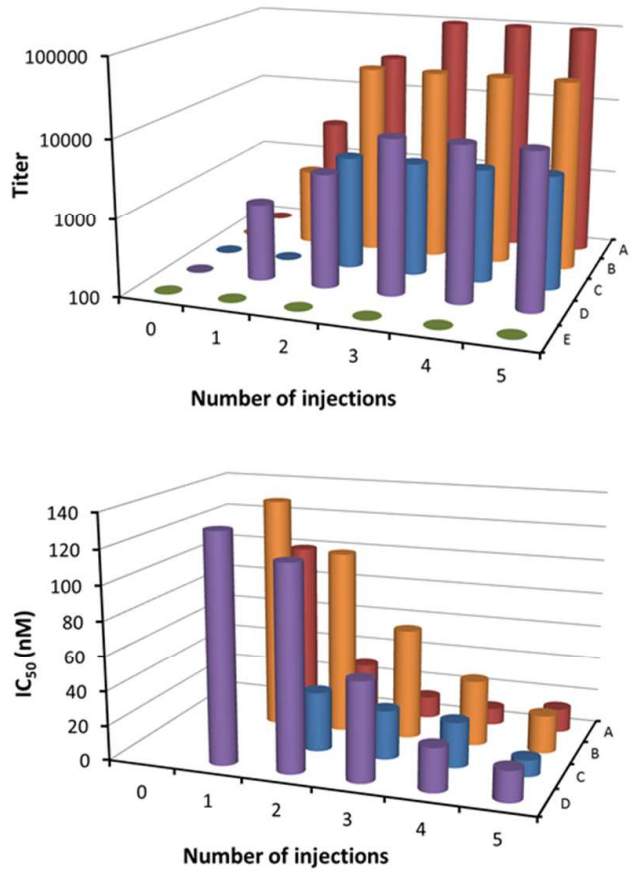

Figure 3. Evolution of the antibody titer and the $\mathrm{IC}_{50}$ value for penthiopyrad during the immunization process using different combinations of CNT constructs (see Table 2 for procedure description). Values are the mean of the results obtained with two antibodies. For the first dose, complete Freund's adjuvant was used, whereas subsequent doses were given with incomplete Freund's adjuvant.

probably occur without the contribution of the MHC or by other unknown interaction mechanisms of this system. Additionally, the CNT-BSA-PPm construct (procedure A) provided higher titers than the protein bioconjugate without nanotubes (procedure C). Despite the lower titers obtained by procedure $C\left(3 \times 10^{3}\right)$, high-affinity antibodies were reached after the fifth boost. Interestingly, if animals received the protein-containing CNT construct in the first injection but subsequent boosts were administered with a non-covalent mixture of aminated CNT and hapten PPm (procedure D), maturation of the immune response was also observed. In this case, titers were lower than those obtained with procedure B in which the hapten was covalently linked to the nanotube. On the contrary, procedure $D$ afforded higher titers than procedure $\mathrm{C}$ in which no nanotubes were present. Moreover, after the fifth injection by 
procedure $\mathrm{D}$, high-affinity antibodies were also obtained. It seems that maturation of the immune response was slower if no protein was used after the first immunization, so more injections were required in order to obtain high-affinity antibodies, both for covalent CNThapten constructs and non-covalent mixtures. Probably, non-covalent interactions between the nanotube and the hapten, such as hydrophobic interactions, could stabilize the mixture enabling the carrier function of the nanotube. Additionally, the hapten could react with cellular or serum proteins or peptides to form covalent conjugates or it could directly interact with antigen receptors as observed in drug allergenic processes. ${ }^{41,42}$ Further studies with other haptens will be required in order to better understand these unexpected results.

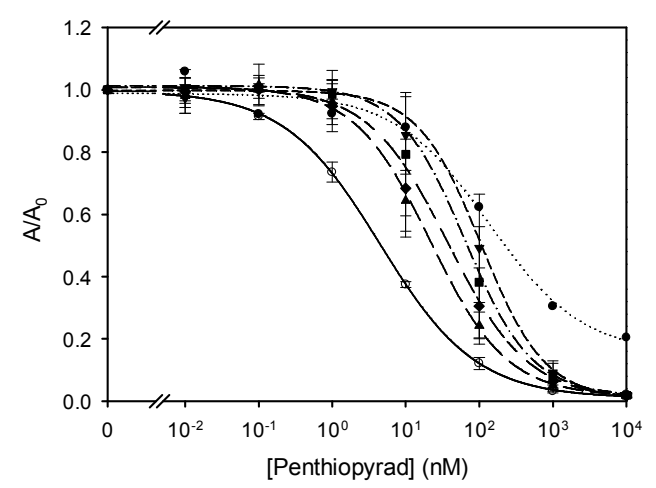

Figure 4. Normalized inhibition curves obtained using the antibodies that were raised after each injection with the construct CNT-PPm in a suspension with Freund's adjuvant, pursuant to procedure B (dashed lines). Injection number: first (circle), second (down triangle), third (square), fourth (diamond), and fifth (up triangle). Values are the mean of the results obtained with two antibodies (from two animals) and three replicate determinations $(n=6)$. The full line depicts the inhibition curve for the antibody with the highest affinity, raised after the fifth injection with the construct CNT-BSA-PPm by procedure A without Freund's adjuvant (see Table 2 for procedure description). 
Regular titers $\left(3 \times 10^{4}\right)$ and high-affinity antibodies $\left(\mathrm{IC}_{50}\right.$ in the low nanomolar range) were obtained by immunizing with CNT constructs carrying only $0.1 \mu \mathrm{g}$ of hapten per boost. Figure 4 depicts the evolution of the inhibition curves from the first to the fifth injection obtained with the antibodies raised by procedure B. Noteworthy, from the second boost, no background signal was observed and penthiopyrad inhibition curves perfectly fitted to a four parameter logistic equation, indicating the applicability of the protein-free CNT-PPm constructs for titer and affinity maturation. These results could be useful for the generation of high-affinity antibodies when only low amounts of hapten are available or when regular concentrations of hapten are not well tolerated by the host animal, such as many toxins. In addition, immunization with CNT-hapten constructs may allow the generation of antibodies recognizing exclusively the target hapten without the interference of the carrier protein.

Adjuvant Effect of CNT-based Immunogens. The generation process of high-affinity and specific antibodies to small chemical molecules commonly requires adjuvants in order to stimulate the immune system and adequately deliver the immunogen. Mineral oils, and particularly Freund's, are the most common type of adjuvants for antibody production. In the present study, the adjuvant effect of CNT-based constructs, with and without carrier protein, was evaluated following different immunization strategies (Table 2, procedures $A$ to $D$, with and without Freund's adjuvant). Ten days after each injection, samples were collected and the titer and affinity of the antibodies were assessed. As expected, immunogens that were prepared with Freund's adjuvant produced high titers, and maturation of the immune response was correctly accomplished with CNT-BSA-hapten constructs (Figure 5, procedure A+). Moreover, a similar response was found, as shown above, if the carrier protein was eliminated at the second and subsequent boosts and Freund's adjuvant was present (procedure $\mathrm{B}+$ ). On the other hand, an adjuvant effect of the CNT-BSA-hapten construct was observed in the absence of Freund's adjuvant. The titer could be increased and the $\mathrm{IC}_{50}$ values could be lowered with such CNT-protein-based construct without Freund's adjuvant 

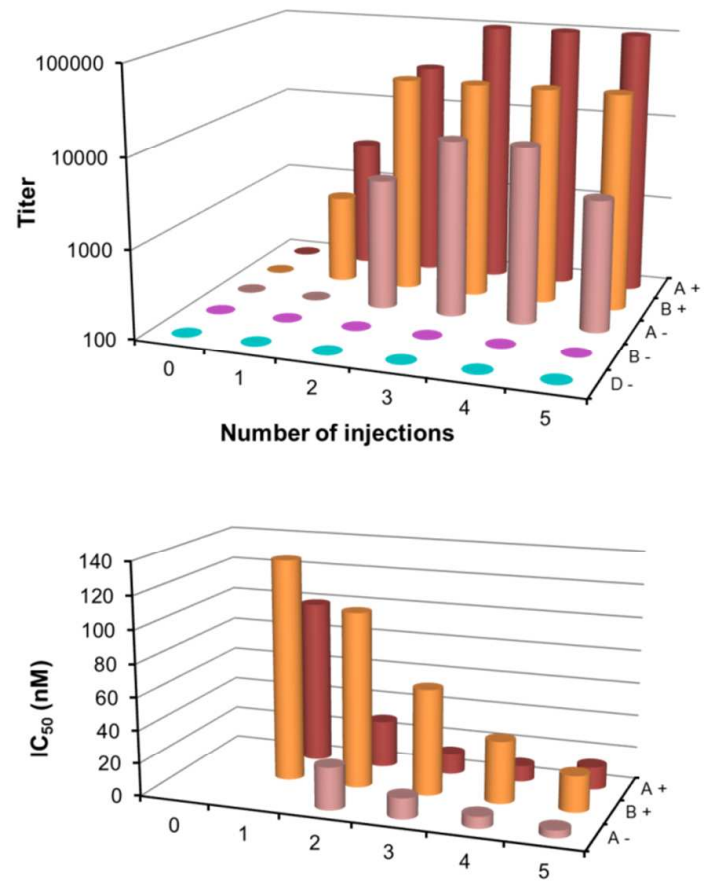

Number of injections

Figure 5. Evolution of the antibody titer and the $\mathrm{IC}_{50}$ value for penthiopyrad during the immunization process using CNT derivatives, with or without Freund's adjuvant (see Table 2 for procedure description). Values are the mean of the results obtained with two antibodies. The presence or absence of adjuvant is indicated in the graphs by a + or a sign, respectively. When applied, complete Freund's adjuvant was used for the first dose and incomplete Freund's adjuvant for subsequent doses.

(Figure 5, procedure A-). On the contrary, when the carrier protein was not present in the CNT construct after the first injection and no adjuvant was employed, no response was found either with the covalent CNT-hapten construct or with the non-linked mixture of CNTs and hapten (Figure 5, procedures B- and D-, respectively). Despite the chemical activation of the CNTs, the presence of the protein seems to be necessary for an adequate adjuvant effect, as previously observed by other authors. ${ }^{9,43}$ Therefore, in order to get an efficient immune 
response to a hapten by using CNTs as delivery vehicles, the adjuvant or the protein can be omitted, but not both.

The antibody with the highest affinity, in absolute terms, to penthiopyrad $\left(\mathrm{IC}_{50}=4.5 \mathrm{nM}\right)$ was generated after the fifth injection when the construct CNT-BSA-PPm was used throughout the whole immunization procedure without adjuvant (procedure A-), even though the antibody affinities that were reached with and without Freund's adjuvant (procedures A+ and $\mathrm{A}^{-}$) were not significantly different. The inhibition curve for penthiopyrad that was obtained with that antibody is depicted in Figure 4 (solid line).

Animal Care. Animal welfare was checked throughout the immunization process. Food and water intake as well as health scores of all animals were normal. As usually, local inflammation was observed with rabbits immunized using Freund's adjuvant. On the contrary, no injury or local reaction was seen in any of the animals immunized without Freund's adjuvant. Thus, CNTs were shown to exert an adjuvant effect with no apparent harm to the experimental animal (Figures S1 and S2).

In conclusion, nanotube-based constructs were shown to be adequate delivery vehicles in order to raise high-affinity antibodies to a small chemical compound such as penthiopyrad. The immune system was effectively stimulated and the affinity of the antibodies was improved when animals were immunized successively with a covalent complex between CNTs and a protein-hapten bioconjugate. Frequently, low amounts of protein-hapten bioconjugate afford high-affinity antibodies but with low titers. We have shown that CNTs help to generate high titers and high-affinity antibodies with low protein bioconjugate loads and using minute amounts of hapten. As expected, the carrier protein was required for the primary immune response to haptens; however, as shown here, an efficient secondary immune response was possible without a protein or peptide. Since the MHC binds peptides, it probably does not participate when protein or peptide-free immunogens are employed, which indicates that the 
MHC could be circumvented for antibody titer and affinity maturation - unknown mechanisms of interaction between small chemical compounds and the MHC could not be discarded, as previously hypothesized for other haptens, such as nicotine, ${ }^{44}$ and non-immunogenic peptides. ${ }^{45}$ Additionally, CNTs can be used as adjuvants in order to enhance the immune response. As a matter of fact, the highest antibody affinity observed in this study was achieved in the absence of Freund's adjuvant and using a CNT-protein-hapten construct for triggering both the primary and the secondary immune responses. Finally, non-covalent protein-free CNT-based constructs were observed to also induce maturation of the immune response to a hapten. These striking results seem to challenge the classical definition of haptens stating that "haptens are defined as compounds which only upon covalent interaction with proteins acquire the potential to induce hapten-specific B cell as well as T cell responses" ${ }^{46}$ Accordingly, further studies will be required so as to figure out the extent and consequences of this finding.

\section{EXPERIMENTAL PROCEDURES}

Reagents and Equipment. Pristine multi-walled CNTs (95\%, 50-80 nm in diameter, 10-20 $\mu \mathrm{m}$ in length) were purchased from Cheap Tubes Inc. (Brattleboro, VT, USA) and used as received. Solvents, ovalbumin (OVA), and reagents for CNT functionalization were obtained from Sigma/Aldrich (Madrid, Spain) and used without further purification. Bovine serum albumin (BSA) was from Roche Applied Sciences (Mannheim, Germany). Microwave reactions were performed in a CEM Discover SP Reactor (Matthews, NC, USA) equipped with an infrared sensor for temperature control, an Activent ${ }^{\circledast}$ pressure control system, magnetic stirring, and a simultaneous air-cooling option (PowerMax) to preserve the same temperature and pressure during the reactions. Pressurized reactions were performed in microwave quartz special vessels supplied by CEM. CNT samples were vacuum filtered with Albet ${ }^{\circledR}$ nylon membranes of $0.45 \mu \mathrm{m}$ pore size acquired from Levantina Lab (Valencia, Spain). In order to monitor the functionalization reactions of CNTs, the zeta potential of the samples was measured using a 
Malvern Zetasizer Nano ZS apparatus (Worcestershire, UK). A JEOL 100 kV JEM-1010 microscope (Tokyo, Japan) equipped with a MegaView III digital camera and with the Analysis image acquisition software was employed for acquisition of TEM images.

Laboratory animals were provided by Granja San Bernardo (Navarra, Spain). Goat antirabbit immunoglobulin polyclonal antibody conjugated to horseradish peroxidase (GAR-HRP) was obtained from BioRad (Madrid, Spain). PPm specific rabbit polyclonal antibody (PPm\#2) was produced in our lab (unpublished results). Polyclonal goat anti-mouse IgG-gold conjugate (5 $\mathrm{nm}$ colloidal gold), adult bovine serum (ABS), Freund's adjuvants, Tween 20, and 0 phenylenediamine were purchased from Sigma/Aldrich (Madrid, Spain). Pestanal grade penthiopyrad ((RS)-N-[2-(1,3-dimethylbutyl)-3-thienyl]-1-methyl-3-(trifluoromethyl)pyrazole-4carboxamide, CAS registry number 131341-86-1, Mw 359.41) was purchased from DuPont (Nambsheim, France). Fungicide concentrated stock solutions were prepared with anhydrous $N, N^{\prime}$-dimethylformamide (DMF) in amber glass vials and stored at $-20^{\circ} \mathrm{C}$. Costar flat-bottom high-binding 96-well polystyrene microtiter plates were from Corning (Corning, NY, USA). Immunoassay absorbances were read with a PowerWave HT from BioTek Instruments (Winooski, VT, USA). Microwells were washed with an ELx405 microplate washer also from BioTek Instruments.

Preparation of Hapten and Protein Conjugates. The synthesis of hapten PPm was carried out in three steps from the previously described methyl 3-(1-methyl-3(trifluoromethyl)-1H-pyrazole-4-carboxamido)thiophene-2-carboxylate ${ }^{47}$ and 3 -methylglutaric anhydride, with an overall yield of $26 \%$. All operations involving air-sensitive reagents were performed under inert atmosphere using syringe and cannula techniques, oven-dried glassware, and freshly distilled and dried solvents. Details of the synthesis and spectroscopic data can be found in the Supporting Information file. Hapten PPm was activated and coupled to the carrier protein by a previously published procedure for related carboxylated haptens. ${ }^{48}$ 
Briefly, the hapten was converted into the corresponding $\mathrm{N}$-hydroxysuccinimidyl ester (PPmNHS) using $N, N^{\prime}$-disuccinimidyl carbonate and $\mathrm{Et}_{3} \mathrm{~N}$ in anhydrous $\mathrm{CH}_{3} \mathrm{CN}$ (Figure 1). The crude reaction product thus obtained was chromatographed by silica gel column chromatography, using $\mathrm{CHCl}_{3}$ as eluent. Next, the purified PPm-NHS active ester was slowly added to a BSA solution in $50 \mathrm{mM}$ carbonate buffer, $\mathrm{pH} 9.6$, and the reaction mixture was incubated at room temperature for $2 \mathrm{~h}$. The resulting protein-hapten conjugate was purified by gel filtration chromatography.

Activation of CNTs. A mixture of CNTs $(50 \mathrm{mg})$ and $65 \% \mathrm{HNO}_{3}(12.5 \mathrm{~mL})$ was placed in a sealed microwave quartz vessel and sonicated for $20 \mathrm{~min}$. The suspension was then irradiated for $30 \mathrm{~min}$ at $250 \mathrm{~W}$ and at $190{ }^{\circ} \mathrm{C}$ under a pressure of 19 bar with vigorous magnetic stirring and simultaneous air-cooling. The cooled reaction mixture was diluted in deionized water (250 $\mathrm{mL})$, filtered through a $0.45 \mu \mathrm{m}$ nylon membrane and washed with more water. The resulting black solid was resuspended in deionized water $(50 \mathrm{~mL})$, sonicated for $15 \mathrm{~min}$, and centrifuged at $1800 \times \mathrm{g}$ for $15 \mathrm{~min}$. The remaining supernatant suspension was filtered again and washed with deionized water, whereas the pellet - remaining starting material - was reacted and purified again as previously, until no pellet was formed after centrifugation. Finally, the airdried solid was suspended in deionized water at a concentration of $1 \mathrm{mg} / \mathrm{mL}$ and sonicated for $5 \mathrm{~min}$ to yield a stable suspension of $\mathrm{CNT}-\mathrm{COOH}(\zeta=-36.3 \pm 0.7 \mathrm{mV})$, which was stored at $4{ }^{\circ} \mathrm{C}$.

Next, $100 \mathrm{mg}$ of CNT-COOH was suspended in dimethylsulfoxide $(6 \mathrm{~mL})$ and ethylenediamine $(4 \mathrm{~mL})$ in a sealed microwave quartz vessel and sonicated for $25 \mathrm{~min}$. The mixture was then irradiated for $30 \mathrm{~min}$ at $280 \mathrm{~W}$ and at $180^{\circ} \mathrm{C}$ under a pressure of 6 bar with vigorous magnetic stirring and simultaneous air-cooling. The cooled reaction mix was diluted in tetrahydrofuran $(40 \mathrm{~mL})$, sonicated for $15 \mathrm{~min}$, and filtered through a $0.45 \mu \mathrm{m}$ nylon membrane. The resulting black solid was resuspended in acetone $(40 \mathrm{~mL})$, sonicated for 15 min, and filtered again. Finally, the air-dried solid was suspended in deionized water at a 
concentration of $1 \mathrm{mg} / \mathrm{mL}$ and sonicated for $5 \mathrm{~min}$ to yield a stable suspension of CNT-NH $2(\zeta=$ $+23.8 \pm 1.1 \mathrm{mV})$, which was stored at $4{ }^{\circ} \mathrm{C}$.

Preparation of CNT-BSA-Hapten Immunizing Construct. A solution of bioconjugate BSA-PPm (hapten-to-protein molar ratio was 18 ) at $0.1 \mathrm{mg} / \mathrm{mL}$ in $10 \mathrm{mM}$ sodium phosphate buffer, $\mathrm{pH} 7.4,(\mathrm{~PB}, 50 \mathrm{~mL})$ was added to a suspension of $\mathrm{CNT}-\mathrm{NH}_{2}(50 \mathrm{mg})$, 1-ethyl-3-(3dimethylaminopropyl)carbodiimide hydrochloride $(450 \mathrm{mg}, 2.35 \mathrm{mmol})$, and $\mathrm{N}$ hydroxysulfosuccinimide sodium salt $(45 \mathrm{mg}, 207 \mu \mathrm{mol})$ in PB $(50 \mathrm{~mL})$. The resulting mixture was stirred at room temperature for $2 \mathrm{~h}$, then glycine hydrochloride was added $(393.1 \mathrm{mg}$, $3.53 \mathrm{mmol}$ ) and stirring was continued for $30 \mathrm{~min}$. Next, the crude mixture was filtered through a $0.45 \mu \mathrm{m}$ nylon membrane and washed with deionized water. The black solid was resuspended in PB (50 mL), sonicated for 5 min, filtered, and washed with deionized water. This process was repeated twice. Finally, the air-dried solid was suspended in sterile PB at a concentration of $2.5 \mathrm{mg} / \mathrm{mL}$ and sonicated for $5 \mathrm{~min}$ to yield a stable suspension of CNT-BSA$\operatorname{PPm}(\zeta=-32.5 \pm 1.0 \mathrm{mV})$, which was stored at $4{ }^{\circ} \mathrm{C}$.

Preparation of protein-free CNT-Hapten Immunizing Construct. A 1 mM solution of freshly activated hapten PPm in DMF (PPm-NHS, $500 \mu \mathrm{L}, 0.5 \mu \mathrm{mol})$ was added dropwise to a suspension of CNT-NH $2(100 \mathrm{mg})$ in $\mathrm{PB}(100 \mathrm{~mL})$. The resulting mixture was vigorously stirred at room temperature during $4 \mathrm{~h}$. The crude mixture was then filtered through a $0.45 \mu \mathrm{m}$ nylon membrane, and washed with deionized water. The solid was resuspended in deionized water $(50 \mathrm{~mL})$, sonicated for $10 \mathrm{~min}$, and filtered again. Finally, the air-dried solid was suspended in sterile PB at a concentration of $2 \mathrm{mg} / \mathrm{mL}$ and sonicated for $5 \mathrm{~min}$ to yield a suspension of CNT$\mathrm{PPm}$ with a tendency to flocculate $(\zeta=+6.9 \pm 0.8 \mathrm{mV})$, which was stored at $4{ }^{\circ} \mathrm{C}$.

Characterization of CNT-based Immunizing Constructs. For Zeta potential measurements, each CNT sample was placed in a Malvern supplied special $750 \mu \mathrm{L}$ folded cell. 
All samples were conveniently diluted in deionized water until the instrument could measure the Zeta potential. All measurements were undertaken at room temperature.

Coupling of BSA-PPm bioconjugate and hapten PPm to CNTs was also assessed by TEM analysis. Aqueous suspensions of the CNT constructs (CNT-BSA-PPm and CNT-PPm) were deposited onto grids (a Formvar support film on a nickel 400 mesh-grid) for 15 min. After overnight evaporation of the solvent, samples were incubated for $2 \mathrm{~h}$ with a solution of antiPPm polyclonal antibody (PPm\#2, diluted 1/3000) in PBS (PB with $140 \mathrm{mM} \mathrm{NaCl)} \mathrm{containing}$ 0.5\% (v/v) Tween 20 (PBS+10xT). Grids were washed three times with PBS containing 0.05\% (v/v) Tween 20 (PBST), and incubated in the darkness for $2 \mathrm{~h}$ with a solution of goat anti-rabbit IgG-gold antibody (diluted 1/500) in PBS+10xT. Finally, after several washings with PBST and overnight evaporation of the solvent, samples were visualized using the electron microscope.

The amount of BSA-PPm bioconjugate or hapten PPm attached to the CNTs was determined following the competitive enzyme-linked immunosorbent assay (ELISA) procedure described below. In the competitive step, the solutions of CNT constructs were added to the OVA-PPm coated plate followed by the addition of the specific rabbit anti-PPm polyclonal antibody (PPm\#2). In the case of CNT-BSA-PPm immunogens, standard curves of bioconjugate BSA-PPm in PBS were employed to interpolate the ELISA signals, whereas standard curves were obtained using the hapten itself for the quantification of the hapten PPm in the CNTPPm construct. All of the samples were analyzed in triplicate.

Rabbit Immunization and Antibody Production. Animal manipulation was performed in compliance with Spanish laws and guidelines (RD 1201/2005 and Law 32/2007) and according to the European Directive 2010/63/EU concerning the protection of animals used for scientific purposes. Animal protocols (ref. A1329731961154) were approved by the Ethics Committee for Animal Experimentation and Welfare of the Ethics Commission of the University of Valencia. Two polyclonal antibodies were generated with each immunogen from 
two 2-kg female New Zealand white rabbits. One milliliter injections were administered subcutaneously at 21-day intervals. When Freund's adjuvant was employed, 1:1 emulsions between sterile PB and Freund's adjuvant were prepared. Complete adjuvant was used for the first dose and incomplete for subsequent boosts. BSA-PPm- or PPm-based CNT constructs were used as immunogens. Control animals were immunized with BSA-PPm bioconjugate, CNT-PPm derivative, and with uncoupled mixtures of $\mathrm{CNT}_{\mathrm{N}} \mathrm{NH}_{2}$ and hapten PPm. All CNT samples were sonicated during $5 \mathrm{~min}$ before the immunogen was prepared. Ten days after each injection, blood samples were collected from the ear vein. Blood was allowed to coagulate overnight at $4{ }^{\circ} \mathrm{C}$, and sera were separated by centrifugation and diluted with sterile PBS containing $0.01 \%(\mathrm{w} / \mathrm{v})$ thimerosal. Parameters for animal welfare were controlled before blood samples were obtained.

Competitive ELISA. Microplate coating was performed in sealed plates by overnight incubation at room temperature with $100 \mu \mathrm{L}$ per well of OVA-PPm bioconjugate solution at $0.1 \mu \mathrm{g} / \mathrm{mL}$ in $50 \mathrm{mM}$ carbonate buffer, $\mathrm{pH}$ 9.6. Then, microwells were rinsed four times with a $150 \mathrm{mM} \mathrm{NaCl}$ and $0.05 \%$ (v/v) Tween 20 solution. The competitive step was carried out with 50 $\mu \mathrm{L}$ per well of penthiopyrad standard solution in PBS plus $50 \mu \mathrm{L}$ per well of antibody dilution in PBST, and incubation during $1 \mathrm{~h}$ at room temperature. After washing as described before, 100 $\mu \mathrm{L}$ per well of GAR-HRP (diluted $1 / 10000$ in PBST carrying $10 \%(\mathrm{v} / \mathrm{v}$ ) ABS) was added and incubated $1 \mathrm{~h}$ at room temperature. Plates were washed again as indicated, and color was generated by adding $100 \mu \mathrm{L}$ per well of freshly prepared 0 -phenylendiamine $(2 \mathrm{mg} / \mathrm{mL})$ solution containing $0.012 \%(\mathrm{v} / \mathrm{v}) \mathrm{H}_{2} \mathrm{O}_{2}$ in $25 \mathrm{mM}$ citrate and $62 \mathrm{mM}$ phosphate buffer, $\mathrm{pH}$ 5.4, and incubation during $10 \mathrm{~min}$ at room temperature. Finally, $100 \mu \mathrm{L}$ per well of $1 \mathrm{M} \mathrm{H}_{2} \mathrm{SO}_{4}$ was added to stop the enzymatic reaction.

Eight-point penthiopyrad calibration curves including a blank were prepared in borosilicate glass tubes by serial dilution in PBS from the most concentrated solution. Absorbance was read 
immediately at $492 \mathrm{~nm}$ with a reference wavelength at $650 \mathrm{~nm}$. Experimental values were fitted to a four-parameter logistic equation using the SigmaPlot software package from SPSS Inc. (Chicago, IL, USA). Antibody titer refers to the particular serum dilution producing a maximum absorbance $\left(A_{\max }\right)$ around 1.0 under the above described assay conditions. The antibody apparent affinity was estimated as the concentration of penthiopyrad at the inflection point of the fitted sigmoidal curve; this parameter is referred to as $\mathrm{IC}_{50}$.

\section{ACKNOWLEDGMENTS}

This work was supported by the Spanish Ministerio de Ciencia e Innovación (AGL201239965-C02-01) and cofinanced by FEDER funds. E.C.-A. is recipient of a predoctoral fellowship from the "Atracció de Talent, VLC-CAMPUS" program of the University of Valencia. TEM images were obtained at the Microscopy Section and animal manipulation was carried out at the Animal Production Section, both of the SCSIE in the University of Valencia.

\section{ASSOCIATED CONTENT}

\section{Supporting information}

Hapten preparation. Animal pictures after subcutaneous immunization. This material is available free of charge via the Internet at http://pubs.acs.org.

\section{ABBREVIATIONS}

ABS: adult bovine serum; BSA: bovine serum albumin; CNT: carbon nanotube; DMF: $N, N$ dimethylformamide; ELISA: enzyme-linked immunosorbent assay; GAR-HRP: goat anti-rabbit immunoglobulin-horseradish peroxidase conjugate; OVA: ovalbumin; PB: phosphate buffer; PBS: phosphate buffered saline; PBST: phosphate buffered saline with Tween 20.

\section{REFERENCES}


(1) Delves, P. J., Martin, S. J., Burton, D. R., and Roitt, I. M. (2011) Innate immunity. Roitt's Essential Immunology $12^{\text {th }}$ Edition (Delves, P. J., Martin, S. J., Burton, D. R., and Roitt, I. M., Eds.) pp 3-34, Chapter 1, Wiley-Blackwell, Chichester.

(2) Delves, P. J., Martin, S. J., Burton, D. R., and Roitt, I. M. (2011) Specific acquired immunity. Roitt's Essential Immunology $12^{\text {th }}$ Edition (Delves, P. J., Martin, S. J., Burton, D. R., and Roitt, I. M., Eds.) pp 35-52, Chapter 2, Wiley-Blackwell, Chichester.

(3) Savina, A., and Amigorena, S. (2007) Phagocytosis and antigen presentation in dendritic cells. Immunol. Rev. 219, 143-156.

(4) Yoshida, T., Mei, H., Doerner, T., Hiepe, F., Radbruch, A., Fillatreau, S., and Hoyer, B. F. (2010) Memory B and memory plasma cells. Immunol. Rev. 237, 117-139.

(5) Batista, F. D., and Harwood, N.E. (2009) The who, how and where of antigen presentation to B cells. Nat. Rev. Immunol. 9, 15-27.

(6) Oberdan, L., Cunningham, A., and Stern, P. L. (2011) Vaccine immunology. Understanding Modern Vaccines: Perspectives in Vaccinology (Garçon, N., Stern, P. L., and Cunningham, A. L., Eds.) pp 25-59, Elsevier, Amsterdam.

(7) Boyles, M. S. P., Stoehr, L. C., Schlinkert, P., Himly, M., and Duschl, A. (2014) The significance and insignificance of carbon nanotube-induced inflammation. Fibers 2, 45-74.

(8) Zolnik, B. S., González-Fernández, A., Sadrieh, N., and Dobrovolskaia, M. A. (2010) Minireview: Nanoparticles and the immune system. Endocrinology 151, 458-465.

(9) Hassan, H. A. F. M., Smyth, L., Rubio, N., Ratnasothy, K., Wang, J. T.-W., Bansal, S. S., Summers, H. D., Diebold, S. S., Lombardi, G., and Al-Jamal, K. T. (2016) Carbon nanotubes' surface chemistry determines their potency as vaccine nanocarriers in vitro and in vivo. J. Control. Release 225, 205-216. 
(10) O'Hagan, D. T., Rahman, D., McGee, J. P., Jeffery, H., Davies, M. C., Williams, P., Davis, S. S., and Challacombe, S. J. (1991) Biodegradable microparticles as controlled release antigen delivery systems. Immunology 73, 239-242.

(11) Peek, L. J., Middaugh, C. R., and Berkland, C. (2008) Nanotechnology in vaccine delivery. Adv. Drug Deliver. Rev. 60, 915-928.

(12) Liu, H., and Irvine, D. J. (2015) Guiding principles in the design of molecular bioconjugates for vaccine applications. Bioconjugate Chem. 26, 791-801.

(13) Sexton, A., Whitney, P. G., Chong, S.-F., Zelikin, A. N., Johnston, A. P. R., De Rose, R., Brooks, A. G., Caruso, F., and Kent, S. J. (2009) A protective vaccine delivery system for in vivo T cell stimulation using nanoengineered polymer hydrogel capsules. ACS Nano 11, 3391-3400.

(14) Slütter, B., Plapied, L., Fievez, V., Alonso-Sande, M., des Rieux, A., Schneider, Y.-J., Van Riet, E., Jiskoot, W., Préat, V. (2009) Mechanistic study of the adjuvant effect of biodegradable nanoparticles in mucosal vaccination. J. Control. Release 138, 113-121.

(15) Dobrovolskaia, M. A. and McNeil, S. E. (2007) Immunological properties of engineered nanomaterials. Nat. Nanotechnol. 2, 469-478.

Ishii, N., Fitrilawati, F., Manna, A., Akiyama, H., Tamada, Y., and Tamada, K. (2008) Gold nanoparticles used as a carrier enhance production of anti-hapten IgG in rabbit: A study with azobenzene-dye as a hapten presented on the entire surface of gold nanoparticles. Biosci. Biotechnol. Biochem. 72, 124-131.

(17) Chen, Y.-S., Hung, Y.-C., Lin, W.-H., and Huang, G. S. (2010) Assessment of gold nanoparticles as a size-dependent vaccine carrier for enhancing the antibody response against synthetic foot-and-mouth disease virus peptide. Nanotechnol. 21, 195101.

(18) Dykman, L. A., Matora, L. Y., and Bogatyrev, V. A. (1996) Use of colloidal gold to obtain antibiotin antibodies. J. Microbiol. Meth. 24, 247-248.

(19) Dykman, L. A., Sumaroka, M. V., Staroverov, S. A., Zaitseva, I. S., and Bogatyrev, V. A. (2004) Immunogenic properties of colloidal gold. Biol. Bull. 31, 75-79. 
(20) Skwarczynski, M., Zaman, M., Urbani, C. N., Lin, I.-C., Jia, Z., Batzloff, M. R., Good, M. F., Monteiro, M. F., and Toth, I. (2010) Polyacrylate dendrimer nanoparticles: A selfadjuvanting vaccine delivery system. Angew. Chem. Int. Edit. 49, 5742-5745.

(21) Ishida, T., Wang, X., Shimizu, T., Nawata, K., and Kiwada, H. (2007) PEGylated liposomes elicit an anti-PEG IgM response in a T cell-independent manner. J. Control. Release $122,349-355$.

(22) Chen, J.-H., Zou, F., Wang, N.-D., Xie, S.-W., and Zhang, X. (2000) Production and application of LPA polyclonal antibody. Bioorg. Med. Chem. Lett. 10, 1691-1693.

(23) Muller, K., Skepper, J. N., Posfai, M., Trivedi, R., Howarth, S., Corot, C., Lancelot, E., Thompson, P. W., Brown, A. P., and Gillard, J. H. (2007) Effect of ultrasmall superparamagnetic iron oxide nanoparticles (Ferumoxtran-10) on human monocyte-macrophages in vitro. Biomaterials 28, 1629-1642.

(24) Maquieira, A., Brun, E. M., Garcés-García, M., and Puchades, R. (2012) Aluminum oxide nanoparticles as carriers and adjuvants for eliciting antibodies from non-immunogenic haptens. Anal. Chem. 84, 9340-9348.

(25) Panyam, J. and Labhasetwar, V. (2003) Biodegradable nanoparticles for drug and gene delivery to cells and tissue. Adv. Drug Deliv. Rev. 55, 329-347.

(26) Mundargi, R. C., Babu, V. R., Rangaswamy, V., Patel, P., and Aminabhavi, T. M. (2008) Nano/micro technologies for delivering macromolecular therapeutics using poly(D,L-lactide-coglycolide) and its derivatives. J. Control. Release 125, 193-209.

(27) Arad-Yellina, R., Firerb, M., Kahanaa, N., and Green, B. S. (2003) Functionalized polysulfone as a novel and useful carrier for immunization and antibody detection. React. Funct. Polym. 54, 5-16.

(28) Greenwood, D. L. V., Dynon, K., Kalkanidis, M., Xiang, S., Plebanski, M., and Scheerlinck, J.-P. Y. (2008) Vaccination against foot-and-mouth disease virus using peptides conjugated to nano-beads. Vaccine 26, 2706-2713. 
(29) Salman, H. H., Irache, J. M., and Gamazo, C. (2009) Immunoadjuvant capacity of flagellin and mannosamine-coated poly(anhydride) nanoparticles in oral vaccination. Vaccine $27,4784-4790$.

(30) George, S. E., Elliott, C. T., McLaughlin, D. P., Delahaut, P., Akagi, T., Akashi, M., and Fodey, T. L. (2012) An investigation into the potential use of nanoparticles as adjuvants for the production of polyclonal antibodies to low molecular weight compounds. Vet. Immunol. Immunopathol. 149, 46-53.

(31) Pantarotto, D., Partidos, C. D., Graff, R., Hoebeke, J., Briand, J.-P., Prato, M., and Bianco, A. (2003) Synthesis, structural characterization, and immunological properties of carbon nanotubes functionalized with peptides. J. Am. Chem. Soc. 125, 6160-6164.

(32) Salvador-Morales, C., Flahaut, E., Sim, E., Sloan, J., Green, M. L. H., and Sim, R. B. (2006) Complement activation and protein adsorption by carbon nanotubes. Mol. Immunol. 43, 193-201.

Parra, J., Abad-Somovilla, A., Mercader, J. V., Taton, T. A., and Abad-Fuentes, A. (2013) Carbon nanotube-protein carriers enhance size-dependent self-adjuvant antibody response to haptens. J. Control. Release 170, 242-251. Pantarotto, D., Partidos, C. D., Hoebeke, J., Brown, F., Kramer, E., Briand, J.-P., Muller, S., Prato, M., and Bianco, A. (2003) Immunization with peptide-functionalized carbon nanotubes enhances virus-specific neutralizing antibody responses. Chem. Biol. 10, 961-966.

(35) Yandar, N., Pastorin, G., Prato, M., Bianco, A., Patarroyo, M. E., and Lozano, J. M., (2008) Immunological profile of a Plasmodium vivax AMA-1 N-terminus peptide-carbon nanotube conjugate in an infected Plasmodium berghei mouse model. Vaccine 26, 5864-5873.

(36) Zeinali, M., Jammalan, M., Ardestani, S. K., and Mosaveri, N. (2009) Immunological and cytotoxicological characterization of tuberculin purified protein derivative (PPD) conjugated to single-walled carbon nanotubes. Immunol. Lett. 126, 48-53. 
Moghimi, S. M. and Hunter, A. C. (2010) Complement monitoring of carbon nanotubes.

Nat. Nanotechnol. 5, 382 (correspondence).

(38) Bianco, A., Kostarelos, K., Partidos, C. D., and Prato, M. (2005) Biomedical applications of functionalised carbon nanotubes. Chem. Commun., 571-577.

(39) Ali, A., Suhail, M., Mathew, S., Shah, M. A., Harakeh, S. M., Ahmad, S., Kazmi, Z., Alhamdan, M. A. R., Chaudhary, A., Damanhouri, G. A. et al. (2016) Nanomaterial induced immune responses and cytotoxicity. J. Nanosci. Nanotechnol. 16, 40-57.

(40) Sakurai, S., Hagiwara, H., and Yanase, Y. (2011) Biological activity of penthiopyrad and study on sensitivity test for several plant pathogens. J. Pest. Sci. 36, 520-523.

(41) Schnyder, B., Burkhart, C., Schnyder-Frutig, K., von Greyerz, S., Naisbitt, D. J., Pirmohamed, M., Park, B. K., and Pichler, W. J. (2000) Recognition of sulfamethoxazole and its reactive metabolites by drug-specific CD4 T cells from allergic individuals. J. Immunol. 164, $6647-6654$.

(42) Britschgi, M., von Greyerz, S., Burkhart, C., and Pichler, W. J. (2003) Molecular aspects of drug recognition by specific T cells. Curr. Drug Targets 4, 1-11.

(43) Wang, J., Sun, R. H., Zhang, N., Nie, H., Liu, J. H., Wang, J. N., Wang, H., Liu, Y. (2009) Multi-walled carbon nanotubes do not impair immune functions of dendritic cells. Carbon 47, $1752-1760$.

(44) Hu, Y., Smith, D., Frazier, E., Hoerle, R., Ehrich, M., Zhang, C. (2016) The nextgeneration nicotine vaccine: a novel and potent hybrid nanoparticle-based nicotine vaccine. Biomaterials 106, 228-239.

(45) Hervás-Stubbs, S., Berasain, C., Golvano, J. J., Lasarte, J. J., Prieto, I., Sarobe, P., Prieto, J., and Borrás-Cuesta, F. (1991) Overcoming class II-linked non-responsiveness to hepatitis B vaccine. Vaccine $12,867-871$.

(46) Weltzien, H. U., Dötze, A., Gamerdinger, K., Hellwig, S., and Thierse H.-J. (2000-2013) Molecular recognition of haptens by $T$ cells: More than one way to tickle the receptor. 
1

2

3

4

5

6

7

8

9

10

11

12

13

14

15

16

17

18

19

20

21

22

23

24

25

26

27

28

29

30

31

32

33

34

35

36

37

38

39

40

41

42

43

44

45

46

47

48

49

50

51

52

53

54

55

56

57

58

59

60

Madame Curie Bioscience Database. Landes Bioscience, Austin, Texas. Available from: https://www.ncbi.nlm.nih.gov/books/NBK6573/

(47) Katsuta, H., Ishii, S., Tomiya, K., and Kodaka, K. (2000) A process for preparing 2-alkyl3-aminotiophene derivative and 3-aminotiophene derivative. Eur. Pat. Appl. EP 1036793 A2.

(48) Esteve-Turrillas, F. A., Parra, J., Abad-Fuentes, A., Agulló, C., Abad-Somovilla, A., and Mercader, J. V. (2014) Hapten synthesis, monoclonal antibody generation, and development of competitive immunoassays for the analysis of picoxystrobin in beer. Anal. Chim. Acta 682, 93103. 
TABLE OF CONTENTS GRAPHIC

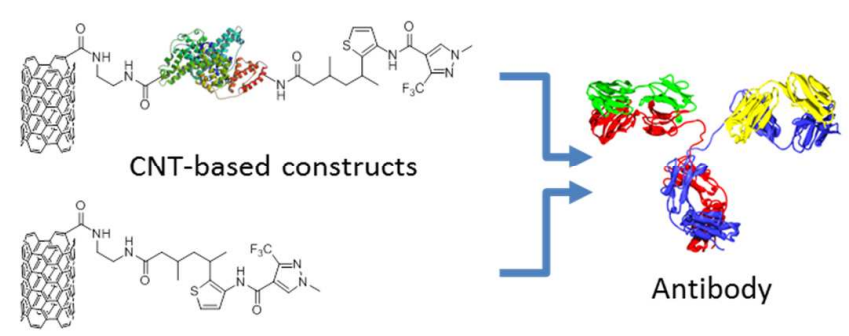




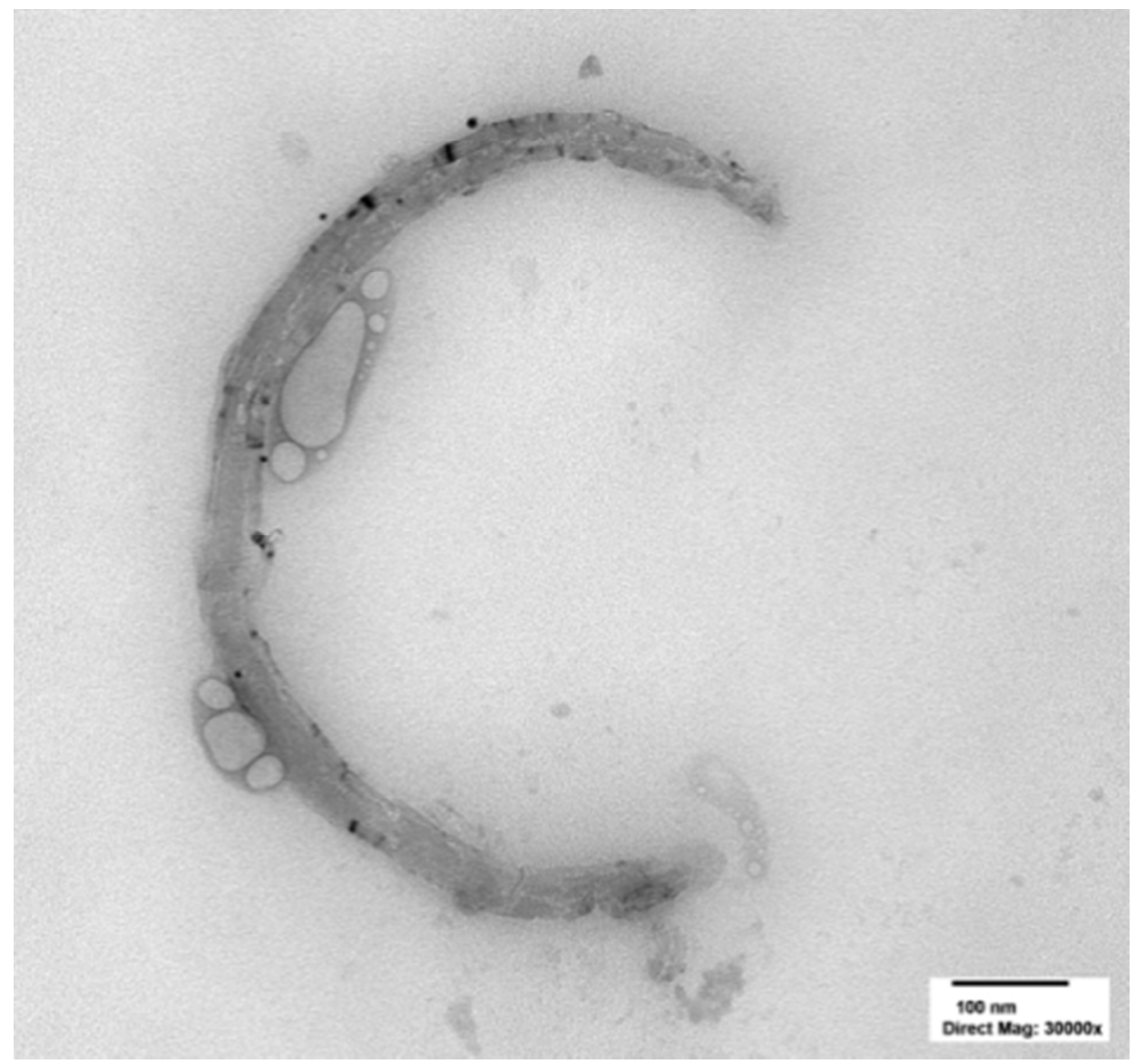

Electron microscopy images $(3 \times 104)$ of a CNT-BSA-PPm immunizing construct $108 \times 102 \mathrm{~mm}(110 \times 110 \mathrm{DPI})$ 
Evolution of the antibody titer and the IC50 value for penthiopyrad during the immunization process using different combinations of CNT constructs (see Table 2 for procedure description). Values are the mean of the results obtained with two antibodies. For the first dose, complete Freund's adjuvant was used, whereas subsequent doses were given with incomplete Freund's adjuvant

$$
86 \times 121 \mathrm{~mm}(150 \times 150 \mathrm{DPI})
$$


Normalized inhibition curves obtained using the antibodies that were raised after each injection with the construct CNT-PPm in a suspension with Freund's adjuvant, pursuant to procedure B (dashed lines). Injection number: first (circle), second (down triangle), third (square), fourth (diamond), and fifth (up triangle). Values are the mean of the results obtained with two antibodies (from two animals) and three replicate determinations $(n=6)$. The full line depicts the inhibition curve for the antibody with the highest affinity, raised after the fifth injection with the construct CNT-BSA-PPm by procedure A without Freund's adjuvant (see Table 2 for procedure description)

$$
153 \times 122 \mathrm{~mm}(150 \times 150 \mathrm{DPI})
$$


Evolution of the antibody titer and the IC50 value for penthiopyrad during the immunization process using CNT derivatives, with or without Freund's adjuvant (see Table 2 for procedure description). Values are the mean of the results obtained with two antibodies. The presence or absence of adjuvant is indicated in the graphs by a + or a - sign, respectively. When applied, complete Freund's adjuvant was used for the first dose and incomplete Freund's adjuvant for subsequent doses

$96 \times 128 \mathrm{~mm}(150 \times 150 \mathrm{DPI})$ 